\title{
OPERATING SPEED PREDICTION MODEL AS A TOOL FOR CONSISTENCY BASED GEOMETRIC DESIGN OF FOUR-LANE DIVIDED HIGHWAYS
}

\author{
Gourab SIL ${ }^{*}$, Avijit MAJI ${ }^{2}$, Suresh NAMA ${ }^{3}$, Akhilesh Kumar MAURYA ${ }^{4}$ \\ ${ }^{1,2}$ Dept of Civil Engineering, Indian Institute of Technology Bombay, Mumbai, India \\ 3,4 Dept of Civil Engineering, Indian Institute of Technology Guwahati, Guwahati, India
}

Received 13 February 2017; revised 22 April 2017, 11 May 2017; accepted 6 June 2017

\begin{abstract}
Researchers have studied two-lane rural highways to predict the operating speed on horizontal curves and correlated it with safety. However, the driving characteristics of four-lane-divided highways are different. Weak lane discipline is observed in these facilities, which influences vehicle speed in adjacent lane or space. So, irrespective of its lane or lateral position, vehicles in four-lane divided highways are considered free flowing only when it maintains the minimum threshold headway from any lead vehicle. Examination of two conditions is proposed to ensure the free flow. Vehicles meeting both conditions, when tracked from the preceding tangent section till the centre of the horizontal curve, are considered as free flowing. The speed data of such free flowing passenger cars at the centre of eighteen horizontal curves on four-lane divided highways is analysed to develop a linear operating speed prediction model. The developed model depends on curve radius and preceding tangent length. The operating speed of passenger car in four-lane divided highways is influenced by horizontal curve of radius $360 \mathrm{~m}$ or less. Further, longer tangent would yield higher operating speed at the centre of the curve. Finally, two nomograms are suggested for conventional design, consistency based design and geometric design consistency evaluation of four-lane divided horizontal curves.
\end{abstract}

Keywords: operating speed, horizontal curve, speed prediction model, weak lane discipline, nomogram, passenger car, four-lane divided highway.

\section{Introduction}

Vehicle speed depends on driver's perception of surroundings, which is influenced by highway geometry, traffic control devices, driving environment, weather condition, etc. In absence of other vehicles, it represents preferred speed of driver. Vehicles are safe, when the preferred speed in a horizontal curve is equal to or less than its safe speed. Now, curves with radius $500 \mathrm{~m}$ or less are considered as sharp (Figueroa Medina, Tarko 2005). Sharp horizontal curves affect the preferred speed (Fitzpatrick et al. 2000a; Jacob, Anjaneyulu 2013; Russo et al. 2016). Hence, any misjudgement in vehicle speed while entering a horizontal curve can turn out to be unsafe. Vehicles, in this situation, may go out of control leading to single vehicle crashes.

Some of the key assumptions of car following theory are (i) vehicles travel in the centre of the lane, and (ii) a vehicle is influenced directly by single lead vehicle. The lanebased-driving also assumes vehicle position close to the centre of the lane (Gunay 2003, 2004, 2007, 2009). How- ever, in the field, it is observed that not all vehicles travel along the centre of the lane. This type of weak lane discipline can be observed in developed countries, especially in multi-lane highways located in peri-urban and urban environments (Gunay 2003, 2004, 2007, 2009). Researchers have attributed this driving behaviour to inadequate lane markings and lane width, poor visibility, poor road surface and deterioration in perfect driving attitudes $(\mathrm{Gu}-$ nay 2003, 2004, 2007; Khan, Maini 1999). Further, weak lane discipline is predominant in developing countries (Mathew et al. 2015; Mallikarjuna, Rao 2011; Mahapatra, Maurya 2013; Bangarraju et al. 2016). Vehicles in weak lane discipline environment are affected by lead vehicles located in the adjacent lanes or positions (Mathew et al. 2015; Gunay 2003, 2007; Bangarraju et al. 2016). Researchers have opined that vehicles veer laterally to select appropriate lane position and speed based on the lead vehicle(s) (Drew 1968; Case et al. 1953; May 1959). Further, Raw-

${ }^{*}$ Corresponding author. E-mail: silgourab@gmail.com 
son (2015) had reported that in multi-lane divided highway, vehicles involved in passing movement may affect each other's speed. Therefore, vehicles involved in passing should not be considered as free flowing. Operating speed is defined as 85th percentile of free flow speed, i.e., $V_{85}$ (AASHTO 2011). Hence, $V_{85}$ prediction models for horizontal curves are developed based on free flow speed. To ensure free flow condition, vehicles are required to be tracked within the study area (comprising of horizontal curve and its preceding tangent section). In this paper, a suitable methodology is developed for free flow speed data collection in four-lane divided horizontal curves.

Several $V_{85}$ prediction models are developed in the past. These models are predominantly for two-lane highways and they are not uniform in model formats, independent variables used and regression coefficients obtained. It is due to the variations in driver behaviour between the studied regions (Misaghi, Hassan 2005). Therefore, no single vehicle speed prediction model is universally accepted and applicable. Now, the $V_{85}$ prediction models for four-lane divided horizontal curves, especially in developing countries, are very limited. It motivated the authors to develop vehicle speed prediction model using vehicle speed and roadway geometry data obtained from four-lane divided highways.

\section{Background}

Horizontal curves are considered as one of the critical highway geometric elements with severe safety concerns (Torbic et al. 2004). It has been found that fatal crashes in horizontal curves are approximately one fourth of the total fatal crashes on highways (Torbic et al. 2004; Fitzsimmons et al. 2012; Fitzsimmons et al. 2013a; Campbell et al. 2012; Glennon et al. 1983). However, the fatal crash per unit length of curve sections (i.e., total crashes at curves/ total length of curve sections) is higher than the fatal crash per unit length of tangent sections (i.e., total crashes at tangents/total length of tangent sections) of the highway (Torbic et al. 2004; Gong, Stamatiadis 2008). Most of the fatal crashes in horizontal curves are single-vehicle crash (Glennon et al. 1983).

Consistent geometric design claims to reduce crash frequency significantly (Dell'Acqua et al. 2013a). Vehicle speed is one of the surrogate performance measures to evaluate geometric design consistency and safety of horizontal curves. Researchers have used the absolute difference between design speed and operating speed (i.e., the 85th percentile free flow speed $V_{85}$ ) to evaluate geometric design consistency and safety of horizontal curves in highways (Lamm et al. 1990, 1998). The most related studies in developed countries as well as in devolving countries have used this criterion (Fitzpatrick et al. 2000a; Jacob, Anjaneyulu 2013; Lamm et al. 1990, 1998). Not all drivers do reduce speed while traversing a horizontal curve. About $87 \%$ of the drivers reduce or maintain their vehicle speed in the horizontal curve while approaching from a tangent section (Bonneson 1999). This means, there are drivers who might have slowed down in the approach tangent for unrelated reasons. They can accelerate in the horizontal curve to attain their preferred speed. In either way drivers tend to maintain safe speed in the curve and this safe speed could be correlated to the horizontal curve geometry such as curve radius.

Vehicles not influenced by environment vehicles are considered as free flowing. Only highway geometry influences the speed of free flowing vehicles (Hashim et al. 2016; Polgár et al. 2013; Tettamanti, Varga 2014). Hence, the free flow speed is defined as the speed adopted by a driver uninfluenced by other vehicles in a traffic stream for a given road conditions (Polgár et al. 2013; Tettamanti, Varga 2014). The Highway Capacity Manual (TRB 2010) suggests that vehicles travelling with headway equal to or greater than a threshold headway value are considered as free flowing. For rural highways, several researchers have adopted the threshold headway value as $5 \mathrm{~s}$ (Fitzpatrick et al. 2000a; Hashim et al. 2016; Gong, Stamatiadis 2008; Poe et al. 1996; Russo et al. 2015, 2016). However, weak lane discipline in multi-lane divided highways can influence vehicles (Mathew et al. 2015; Mallikarjuna, Rao 2011; Gunay 2003, 2007; Bangarraju et al. 2016; Drew 1968; Case et al. 1953; May 1959; Rawson 2015) prior to centre of the horizontal curve. Therefore, at selected speed measurement points consideration of lane based threshold headway value alone may not be appropriate to evaluate the free flow condition in multi-lane divided highways. Hence, effect of lead vehicle traveling in the adjacent lane prior to centre of the curve need to be considered. Vehicle tracking can help to identify this interaction with other vehicles prior to the curve centre. Therefore, additional criteria apart from the minimum threshold headway need to be developed for improving the evaluation of free flow condition.

The studies related to speed prediction models consider radius as the most dominant independent variable (Gong, Stamatiadis 2008; Abdul-Mawjoud, Sofia 2008; Bennett 1994). Researchers have found that $V_{85}$ increases with increase in curve radius; however, remains unchanged for flatter curve (Abdul-Mawjoud, Sofia 2008; Fitzpatrick et al. 2000b; Collins et al. 1999). Flatter curves have radius of $1700 \mathrm{ft}$ (i.e., $518 \mathrm{~m}$ ) or more (Figueroa Medina, Tarko 2005). Russo et al. (2016) reported that curves having radius more than $500 \mathrm{~m}$ do not influence driving performance in horizontal alignment. A study in India by Jacob and Anjaneyulu (2013) indicates that radius of $400 \mathrm{~m}$ or below influence the preferred speed on horizontal curves. Therefore, the present study considers sharp curves with radius $500 \mathrm{~m}$ or below for developing speed prediction model. Most of the available speed prediction models are developed for two-lane rural highways (Fitzpatrick et al. 2000a, 2000b; Lamm et al. 1990, 1998; Hashim et al. 2016; Abdul-Mawjoud, Sofia 2008; Abbas et al. 2011; Jacob, Anjaneyulu 2013; Memon et al. 2008). Table 1 represents the summary of a few relevant models. Gong and Stamatiadis (2008) developed $V_{85}$ prediction models for four-lane horizontal curves on rural non-freeways in the United States. Researchers have reviewed the vehicle speed behaviour on horizontal curves for four-lane divided highways in 
Table 1. $V_{85}$ prediction models of horizontal curves for passenger cars

\begin{tabular}{|c|c|}
\hline Author & Model \\
\hline Bennett $(1994)^{*}$ & $V_{85}=61.58+0.485 \cdot V_{a}-\frac{4516}{R}$ \\
\hline Taragin and Leisch $(1954)^{*}$ & $V_{85}=88.87-\frac{2554.76}{R}$ \\
\hline Kerman et al. $(1982)^{*}$ & $V_{85}=V_{a}-\frac{V_{a}^{3}}{398 \cdot R}$ \\
\hline Russo et al. $(2016)^{*}$ & $V_{85}=114.75-\frac{7036.54}{R}$ \\
\hline Glennon et al. $(1983)^{*}$ & $V_{85}=103.96-\frac{4524.94}{R}$ \\
\hline McFadden and Elefteriadou $(2000)^{*}$ & $85 M S R=-14.90+0.144 \cdot V_{85_{@ P C 200}}+0.0153 \cdot A T L+\frac{954.44}{R}$ \\
\hline Eboli et al. $(2017)^{*}$ & $V_{85}=0.037 \cdot R+0.858 \cdot V_{a_{-} 85}$ \\
\hline Voigt $(1996)^{*}$ & $V_{85}=99.61-\frac{2951.37}{R}$ \\
\hline Lamm et al. $(1988)^{*}$ & $V_{85}=34.70+D C+2.081 \cdot L W+0.174 \cdot S W+0.0004 \cdot A A D T$ \\
\hline Passetti and Fambro $(1999)^{*}$ & $V_{85}=103.90-\frac{3020.50}{R}$ \\
\hline Misaghi and Hassan $(2005)^{*}$ & $\begin{array}{l}V_{85}=91.85+9.813 \cdot 10^{-3} \cdot R \\
V_{85}=94.30+8.673 \cdot 10^{-6} \cdot R^{2}\end{array}$ \\
\hline Voigt and Krammes $(1996)^{*}$ & $V_{85}=99.6-1.69 \cdot D C+0.14 \cdot C L-0.13 \cdot \Delta+71.82 \cdot e$ \\
\hline Schurr et al. $(2002)^{*}$ & $V_{85}=103.3-0.1253 \cdot \Delta+0.0238 \cdot C L-71.82 \cdot G$ \\
\hline Lamm and Choueiri $(1987)^{*}$ & $V_{85}=96.152-\frac{2803.769}{R}$ \\
\hline Lamm et al. $(1990)^{*}$ & $V_{85}=94.398-\frac{3188.656}{R}$ \\
\hline Islam and Seneviratne $(1994)^{*}$ & $V_{85}=103.03-\frac{4208.76}{R}+\frac{36597.92}{R^{2}}$ \\
\hline Krammes et al. $(1995)^{*}$ & $V_{85}=41.62-1.29 \cdot D C+0.049 \cdot C L-0.12 \cdot \Delta+0.95 \cdot V_{a}$ \\
\hline Jacob and Anjaneyulu (2013) & $V_{85}=56.75-\frac{739.21}{R}-0.034 \cdot C L$ \\
\hline Memon et al. $(2008)^{* *}$ & $V_{85}=40.4-\frac{1571}{R}+0.613 \cdot V_{a_{-} \max }+0.0244 \cdot C L-0.163 \cdot \Delta$ \\
\hline Gong and Stamatiadis $(2008)^{* * *}$ & $V_{85}=60.779+1.804 \cdot S T-2.521 \cdot M T-1.071 \cdot A G-1.519 \cdot F C+0.00047 \cdot R+2.408 \cdot \frac{C L}{R}$ \\
\hline
\end{tabular}

Notes:

*two-lane highways in developed countries;

${ }^{* *}$ two-lane highways in developing countries;

${ }^{* * *}$ four-lane highways in developed countries;

$A A D T$ - average annual daily traffic; $A G$ - approaching grade; $A T L$ - approach tangent length; $C L$ - curve length; $F C$ - front curve index; $G$ - gradient; $L W$ - lane width; $M S R$ - maximum speed reduction; $M T$ - median type index; $P C$ - point of curvature; $S T$ shoulder type index; $S W$ - shoulder width; $\Delta$ - deflection angle;

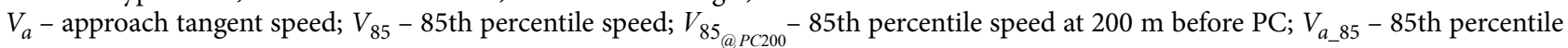
speed at approach tangent; $V_{a \_ \text {max }}-$ maximum approach tangent speed.

developing countries (Nama et al. 2016). However, availability of speed prediction model for four-lane divided horizontal curves is very limited, especially in developing countries. Generally, researchers have adopted Ordinary Least Square (OLS) regression technique for developing the speed prediction models (Misaghi, Hassan 2005;
Fitzpatrick et al. 2000a; Lamm et al. 1990, 1998; Hashim et al. 2016; Abdul-Mawjoud, Sofia 2008; Abbas et al. 2011; Eboli et al. 2017; Russo et al. 2016). The independent variables used in these models are combinations of curve radius, curve length, length of approach tangent, degree of curvature, deflection angle, gradient, lane width, shoulder 
width, pavement type index, grade of approach tangent, 85th percentile speed on approach tangent, average annual daily traffic, etc. (Misaghi, Hassan 2005; Fitzpatrick et al. 2000a; Lamm, Choueiri 1987). Further, in these models, the independent variable coefficients vary widely (Fitzpatrick et al. 2000a; Lamm et al. 1990, 1998; Hashim et al. 2016; Abdul-Mawjoud, Sofia 2008; Abbas et al. 2011; Jacob, Anjaneyulu 2013).

\section{Study objectives}

In some earlier studies, researchers have considered certain threshold headway for free-flow condition and used it in spot-speed data collection for developing the speed prediction models of horizontal curves (Fitzpatrick et al. 2000a; Jacob, Anjaneyulu 2013; Steyer 1998; Watters, O'Mahony 2007). These studies did not consider the effect of inter vehicle interaction in the prior segment. However, a few studies considered tracking of vehicles throughout the study zone (i.e., in the horizontal curve and its preceding tangent) for the free-flow condition (Fitzsimmons et al. 2013a, 2013b; Russo et al. 2015, 2016). They have used Global Positioning System (GPS) fitted vehicles and roadside laser detectors, sensors or video cameras for the purpose (Fitzsimmons et al. 2013a; Glennon et al. 1983; Hashim et al. 2016; Russo et al. 2015; Camacho-Torregrosa et al. 2013; Pérez-Zuriaga et al. 2013).

However, vehicle fitted with GPS devices can make driver over sensitive about vehicle speed (Nama et al. 2016). Data collection using roadside laser detectors and sensors cannot identify vehicle categories accurately. Moreover, in these techniques, passing movement of vehicles cannot be recognised and vehicles cannot be tracked in the study zone. Hence, there is a need to develop an external data collection setup that does not influence speed choice behaviour of a driver and can track the vehicle in the study zone.

A large number of researches on vehicle speed prediction models at horizontal curves have been carried out in the last several decades (Taragin, Leisch 1954, Fitzpatrick et al. 2000a, 2000b; Lamm et al. 1990, 1998; Hashim et al. 2016; Abdul-Mawjoud, Sofia 2008; Abbas et al. 2011; Jacob, Anjaneyulu 2013; Memon et al. 2008). The available models vary widely in terms of independent variables considered and value of coefficients reported. However, $V_{85}$ prediction models for four-lane divided horizontal curves are very limited. Therefore, the primary objectives of this study are:

1) to establish field data collection setup for tracking free flowing vehicles within a study zone;

2) to develop passenger car $V_{85}$ prediction model for four-lane divided horizontal curves.

\section{Site selection and data collection}

Russo et al. (2016) reported that flat terrain (i.e., gradient $\leq 5 \%$ ) does not have significant effect on speed of passenger cars. Hence, highways examined in this study are located in flat terrain. In total 12 sites on National High- way 3 (NH-3) and 6 on National Highway 40 (NH-40) are selected for this study. The NH-3 sites are located between Mumbai and Nashik of Maharashtra in the western region of India. Whereas, the NH-40 sites are located between Guwahati and Shillong in the north-eastern region of India. Out of eighteen, fifteen sites are considered for model development and the reaming three for model validation. The cross section of all sites belongs to four-lane divided highways with $7 \mathrm{~m}$ wide carriageway on either side. A typical site is shown in Figure 1. The following points are considered while selecting these sites:

- uniform cross-section details, such as, four-lane divided carriageway $(7 \mathrm{~m})$ with adequate shoulder and super-elevation;

- uniform roadside features, such as, presence of guardrail, embankment and shrubs in median;

- no intersection or median openings within $1 \mathrm{~km}$ of the study sites;

- free from roadside interference due to on-street parking, illegal contra movements, bus bays etc.;

- no pedestrian or non-motorized vehicle movements;

- availability of vantage points that are not in direct view of drivers for installing video cameras;

- good weather and pavement conditions; and

- traffic flow less than $800 \mathrm{veh} / \mathrm{h}$;

The data collection process is divided into two parts: (i) highway geometric data collection and (ii) vehicle spot speed data collection. Geometric data of the sites are obtained from National Highways Authority of India (NHAI) and Mumbai Nasik Expressway Limited (MNEL) in the form of plan and profile drawings. The obtained information is cross-checked on the site using surveying equipment. At all sites, geometric data available in plan and profile drawings matched with the survey data. The vehicle spot speed data collection is described in the subsequent sections.

The field data-collection setup for this study is primarily developed keeping the free flow condition of weak lane discipline of four-lane divided highways in mind. This would require tracking of subject vehicles within the study zone. Therefore, in this study, the free flow condition is assured by considering the following two conditions:

- Condition A: maintaining a threshold headway of $5 \mathrm{~s}$ between the subject vehicle and its lead vehicles at the observation stations;

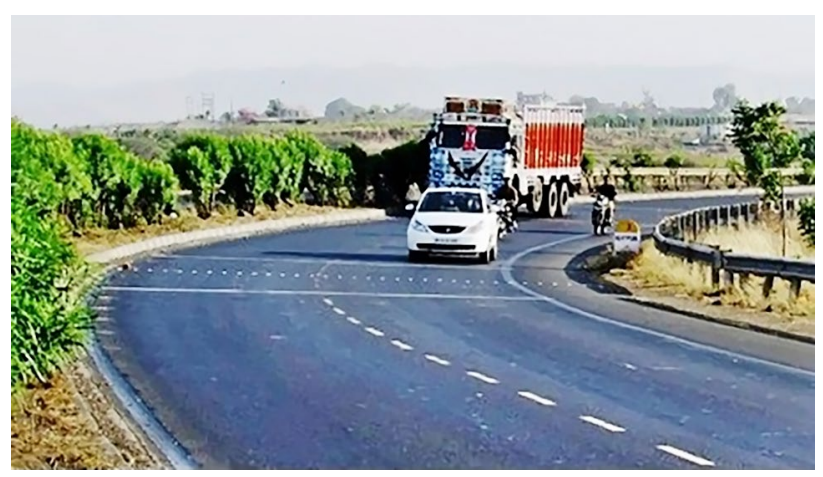

Figure 1. Typical image of the sites 


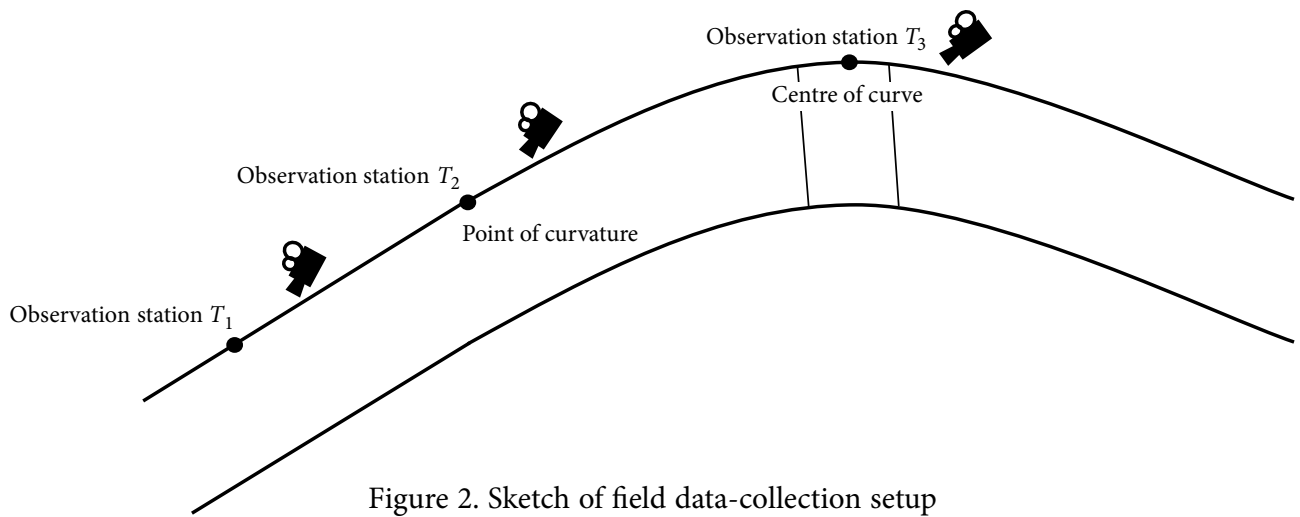

- Condition B: no passing movement between the observation stations.

Hashim et al. (2016) indicated that vehicles start adjusting speed at the beginning of a circular horizontal curve and can extend till the curve centre. Therefore, in this study, vehicle speed in the preceding tangent, about $50 \mathrm{~m}$ prior to the point of curvature, is considered as the stable speed on the tangent section. The vehicle tracking starts from this location (referred as $T_{1}$ in Figure 2) and ends at the centre of the circular horizontal curve (referred as $T_{3}$ in Figure 2). An intermediate observation point is also setup at the point of curvature (referred as $T_{2}$ in Figure 2) for the same purpose. A trap length of 15 $\mathrm{m}$ is marked at the centre of curve for vehicle speed data collection. To satisfy free flow movement, the following vehicle should maintain the minimum threshold headway from any lead vehicle, irrespective of its lane or lateral position. Therefore, three synchronized video cameras are installed at these locations to monitor time headway (i.e., Condition $\mathrm{A}$ at $T_{1}, T_{2}$ and $T_{3}$ ) and any possible intervehicle interaction (i.e., Condition B between $T_{1} \ldots T_{2}$ and $T_{2} \ldots T_{3}$ ). Further, the video $\log$ from camera at $T_{3}$ is used to obtain vehicle speed. Cameras at location $T_{2}$ and $T_{3}$ are installed in such an angle that vehicles leaving prior observation station can be tracked and monitored for Condition B. Vehicles satisfying both conditions (i.e., Conditions A and B) are selected for data processing and model development.

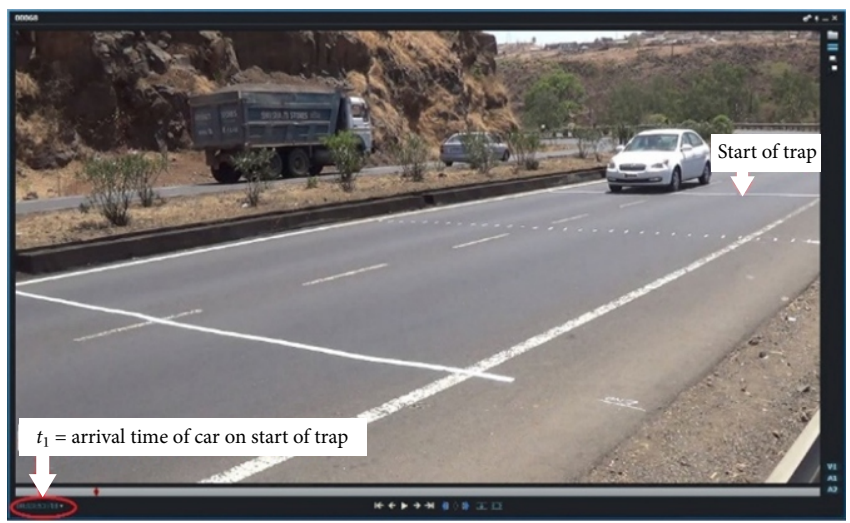

\section{Data extraction}

In this study, passenger cars are the subject vehicles. Condition A is evaluated by comparing the threshold headway with the time headway between the subject vehicle and its lead vehicles. For this, the video recordings of passenger cars are observed frame by frame at all the three locations of a site (i.e., $T_{1}, T_{2}$ and $T_{3}$ ). The time to cross a predefined fixed object at these locations by the lead vehicles and the subject passenger car is noted. Passenger cars meeting the time headway of $5 \mathrm{~s}$ or more at all the three locations (i.e., meeting Condition A at all three locations) are tracked from $T_{1}$ to $T_{3}$ in the three synchronized video logs for Condition B. If the subject vehicle did not interact with any other vehicle within the study zone, it is considered to meet Condition B. Speed of such passenger cars are estimated at location $T_{3}$ from the travel time of $15 \mathrm{~m}$ wide trap. The time stamps of passenger car's front tires crossing the first and second lines of the trap are noted (see Figure 3 for details). All cameras used in this study are set to record video at 25 frames/s. Hence, the maximum error possible in the time noted is $0.04 \mathrm{~s}$. Present study uses Equation (1) for estimating speed of passenger cars. These speed data are recorded for further processing. The descriptive statistics of the recorded speed data for each site is shown in Table 2. It can be seen that the mean speed varies between 48 and $86 \mathrm{~km} / \mathrm{h}$. Whereas, the minimum and maximum observed speed are 27 and $123 \mathrm{~km} / \mathrm{h}$, respectively.

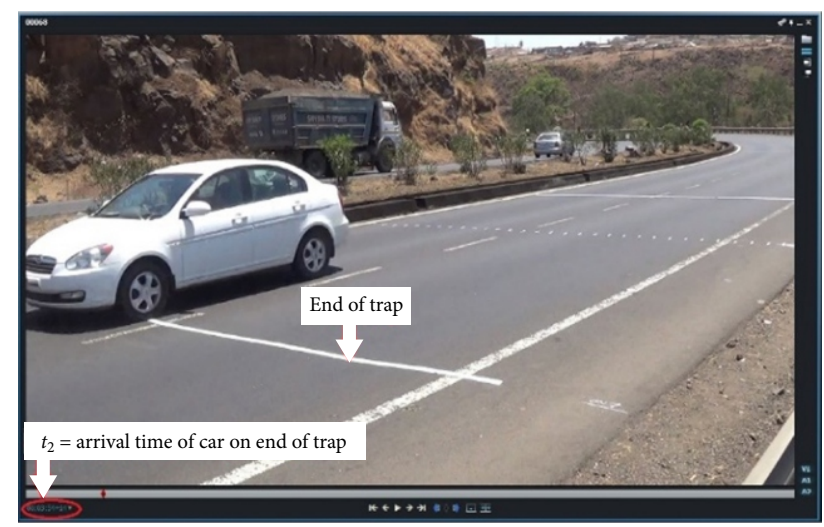

Figure 3. Passenger car tire touching the first and second line of trap length 
Table 2. Statistics of passenger car speed data

\begin{tabular}{|c|c|c|c|c|c|c|c|}
\hline Model & Site No & Mean $[\mathrm{km} / \mathrm{h}]$ & Std. Dev. $[\mathrm{km} / \mathrm{h}]$ & $V_{85}[\mathrm{~km} / \mathrm{h}]$ & Maximum $[\mathrm{km} / \mathrm{h}]$ & Minimum $[\mathrm{km} / \mathrm{h}]$ & Location \\
\hline \multirow{15}{*}{ Development } & 1 & 55 & 5.63 & 61 & 71 & 45 & \multirow{11}{*}{ NH-3 } \\
\hline & 2 & 55 & 5.73 & 61 & 71 & 42 & \\
\hline & 3 & 69 & 8.03 & 75 & 90 & 47 & \\
\hline & 4 & 61 & 6.51 & 68 & 75 & 45 & \\
\hline & 5 & 67 & 7.86 & 75 & 84 & 50 & \\
\hline & 6 & 76 & 10.79 & 84 & 104 & 59 & \\
\hline & 7 & 76 & 9.57 & 87 & 96 & 52 & \\
\hline & 8 & 74 & 8.66 & 84 & 96 & 50 & \\
\hline & 9 & 86 & 15.24 & 96 & 123 & 52 & \\
\hline & 10 & 85 & 12.89 & 96 & 113 & 54 & \\
\hline & 11 & 77 & 13.05 & 90 & 104 & 40 & \\
\hline & 12 & 48 & 8.68 & 56 & 69 & 32 & \multirow{4}{*}{ NH-40 } \\
\hline & 13 & 58 & 9.95 & 69 & 73 & 27 & \\
\hline & 14 & 51 & 7.75 & 58 & 71 & 32 & \\
\hline & 15 & 53 & 10.9 & 63 & 82 & 31 & \\
\hline \multirow{3}{*}{ Validation } & 16 & 80 & 9.58 & 90 & 104 & 47 & NH-3 \\
\hline & 17 & 51 & 7.13 & 59 & 65 & 33 & \multirow{2}{*}{ NH-40 } \\
\hline & 18 & 54 & 8.38 & 63 & 68 & 32 & \\
\hline
\end{tabular}

The 85th percentile speed or operating speed used in developing and validating the speed prediction model varies between 56 and $96 \mathrm{~km} / \mathrm{h}$.

$$
V=\frac{15 \cdot 3.6}{t_{2}-t_{1}},
$$

where: $V$ - passenger car speed $[\mathrm{km} / \mathrm{h}] ; t_{1}$ - time $[\mathrm{s}]$, when front tire touched first line of the trap; $t_{2}$ - time $[\mathrm{s}]$, when front tire touched second line of the trap.

\section{Effect of curve radius on operating speed}

This study identifies the effect of curve radius on $V_{85}$ of passenger car in the four-lane divided highways. For this, speed data of free flowing passenger car at the centre of circular curve (i.e., $T_{3}$ ) is considered. Now, Figure 4 represents the $V_{85}$ at the centre of the curve versus radius of the curve plot. This plot indicates that the $V_{85}$ increases with increase in curve radius. It supports earlier findings that are based on two-lane highway data (Abdul-Mawjoud, So-

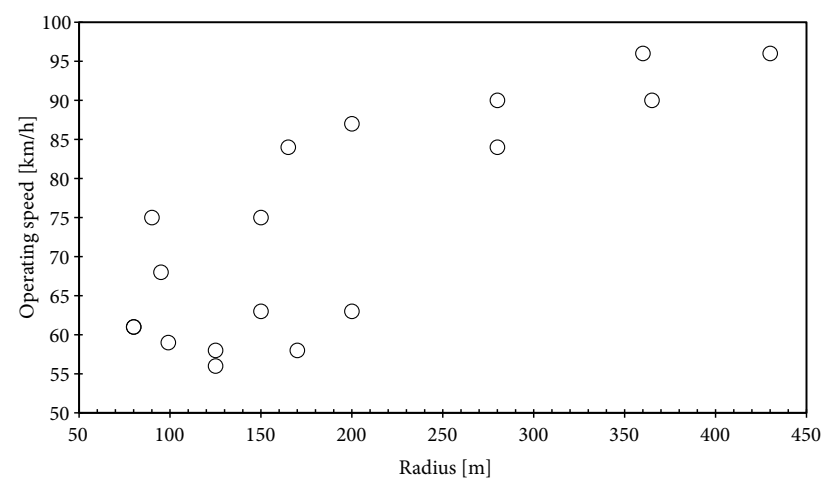

Figure 4. Effect of curve radius on operating speed fia 2008; Fitzpatrick et al. 2000a; Collins et al. 1999). Generally, the speed dispersion for smaller radii is expected to be low. In Figure 4, relatively wider dispersion of data points at smaller radii may be due to higher number of smaller radii sites but limited number of larger radii sites. The other possibilities could be the variations in magnitude of different geometric parameters such as, preceding tangent length, gradient and presence of preceding curve. Further, it is observed that the maximum $V_{85}$ of passenger cars is about $95 \mathrm{~km} / \mathrm{h}$ for curves with radius 360 and $430 \mathrm{~m}$. Though not conclusive due to sample size, this speed value is similar to the maximum vehicle speed reported by others (Krammes et al. 1995; Fitzpatrick, Collins 2000).

\section{Correlation analysis}

One of the objectives of this study is to develop operating speed prediction model of passenger cars for four-lane divided highway. The effect of highway geometric parameters on free-flow speed of vehicle is paramount. Hence, the present study considers longitudinal and cross sectional geometric features associated to a horizontal curve as the possible explanatory parameters for the $V_{85}$ model development. These possible explanatory parameters are radius $R$, curve length $C L$, gradient $G$, preceding tangent length $P T L$, shoulder width on the outer side $S W O$ and shoulder width on the inner side $S W I$. All the selected sites have uniform carriageway width of $7 \mathrm{~m}$. Hence, carriageway width is not considered as explanatory parameter in this study. Values of selected parameters are obtained from plan and profile drawings. The descriptive statistics of these geometric design features for the fifteen sites considered in model development are given in Table 3. 
A Pearson correlation analysis has been carried out to find the co-linearity between $R, C L, P T L, G, S W O$ and $S W I$. Table 4 represents the obtained results. The correlation coefficients indicate that $G$ is highly correlated with SWO However, the design guidelines consider these parameters as independent. Hence, all the explanatory parameters are used in developing the speed prediction model.

\section{Development speed prediction model}

Speed data of passenger cars are collected in good weather and pavement conditions. These speed data of all sites are tested for normal distribution. A Shapiro-Wilk test at $95 \%$ confidence interval is conducted for this purpose. The test results revealed that the $\mathrm{p}$-values for all sites are more than 0.05 . Therefore, the speed data of all sites are normally distributed and can be used in developing the speed prediction model by regression analysis. For this, the $V_{85}$ (i.e., 85th percentile speed) at centre of circular curve (i.e., at $T_{3}$ ) and geometric features (i.e., $R, C L, G$, $P T L, S W O$ and $S W I$ ) of the fifteen horizontal curves are considered as dependent and independent parameters, respectively. A step wise multiple linear regression analy- sis at $95 \%$ confidence interval has been performed using statistical software SPSS (https://www.ibm.com/analytics/spss-statistics-software). The developed model and its corresponding $R^{2}$-values are shown in Table 5. The high value of adjusted $R^{2}$-value (0.81) indicates good fitness of the developed model. Further, the $F$-value of 30.91 and $p$-value less than 0.05 illustrate higher significance of the developed model. It can be observed that the speed prediction model for centre of circular curve depends on horizontal curve radius $R$ and preceding tangent length PTL. The $p$-values of $R$ and PTL are less than 0.05. All other parameters (i.e., $C L, G, S W O$ and $S W I$ ) have $p$-values higher than 0.05 . Hence, $R$ and $P T L$ are considered as significant in developed model at $95 \%$ confidence interval. The coefficients of $R$ and PTL indicate that the $V_{85}$ of passenger car at the centre of the curve is comparatively more sensitive to $R$. In this developed model, the predicted $V_{85}$ of passenger cars increases with PTL. Hence, increasing PTL leads to higher $V_{85}$ at the centre of a sharp horizontal curve. It may increase the risk of vehicle run-off or overturning at this location. In other words, adopting longer preceding tangent for a sharp radius curve may not be safe. Probably, this is why the design guidelines explicitly advise against longer PTL for sharper horizontal curves.

Table 3. Descriptive statistics of independent variables for model development

\begin{tabular}{|l|c|c|c|c|c|c|}
\hline \multicolumn{1}{|c|}{ Variables } & $R[\mathrm{~m}]$ & $C L[\mathrm{~m}]$ & $G[\%]$ & $P T L[\mathrm{~m}]$ & $S W O[\mathrm{~m}]$ & $S W I[\mathrm{~m}]$ \\
\hline Mean & 194 & 165 & -1 & 236 & 2 & 2 \\
\hline Std. Dev. & 109 & 132 & 3 & 117 & 2 & 1 \\
\hline Maximum & 430 & 523 & 5 & 500 & 4 & 3 \\
\hline Minimum & 80 & 27 & -5 & 80 & 0 & 0 \\
\hline
\end{tabular}

Table 4. Pearson correlation analysis result

\begin{tabular}{|c|c|c|c|c|c|c|}
\hline & \multicolumn{6}{|c|}{ Pearson correlation } \\
\hline & $R$ & $C L$ & G & $P T L$ & SWO & $S W I$ \\
\hline$R$ & 1 & 0.512 & 0.279 & -0.104 & -0.239 & -0.224 \\
\hline$C L$ & 0.512 & 1 & 0.039 & -0.012 & -0.030 & 0.138 \\
\hline$G$ & 0.279 & 0.039 & 1 & -0.270 & $-0.750^{*}$ & 0.269 \\
\hline$P T L$ & -0.104 & -0.012 & -0.270 & 1 & 0.513 & -0.375 \\
\hline SWO & -0.239 & -0.030 & $-0.750^{*}$ & 0.513 & 1 & -0.443 \\
\hline SWI & -0.224 & 0.138 & 0.269 & -0.375 & -0.443 & 1 \\
\hline
\end{tabular}

Note: * correlation is significant at the 0.01 level.

Table 5. Developed model details

\begin{tabular}{|c|c|c|c|c|c|c|}
\hline Model & \multicolumn{6}{|c|}{$V_{85 C}=40.549+0.108 \cdot R+0.053 \cdot P T L$} \\
\hline$R^{2}$-value & \multicolumn{6}{|c|}{0.84} \\
\hline Adjusted $R^{2}$-value & \multicolumn{6}{|c|}{0.81} \\
\hline$F$-value for model & \multicolumn{6}{|c|}{30.91} \\
\hline$p$-value for model & \multicolumn{6}{|c|}{0.00} \\
\hline Predictor variables & $R$ & $P T L$ & $C L$ & $G$ & SWO & SWI \\
\hline$p$-value & 0.00 & 0.00 & 0.12 & 0.18 & 0.78 & 0.20 \\
\hline Whether included in model & yes & yes & no & no & no & no \\
\hline
\end{tabular}


However, shorter PTL for sharp horizontal curves may bring harmony in vehicle speed. Overall, the developed model has the capability of providing the required combinations of $R$ and PTL for harmony in passenger car speed. Further, it may help evaluating geometric designs for consistency. However, the proposed model is applicable for $R \geq 80 \mathrm{~m}$ and $P T L \leq 500 \mathrm{~m}$ in good weather and pavement conditions, and cross section details considered in site selection (see Section 3).

\section{Model validation}

The remaining three sites (i.e., Sites No $16 \ldots 18$ in Table 2) are used for validating the developed $V_{85}$ prediction model. Its geometric features are similar to the sites adopted for model development. The sites used for validation are from two different parts of the country. Hence, successful validation of these sites would indicate usefulness of the model for various geographic locations. The details of the explanatory parameters (i.e., $R$ and $P T L$ ) and observed versus predicted $V_{85}$ for the sites used in validation are presented in Table 6. Comparison of predicted and observed $V_{85}$ in the Table 6 , reveals the small deviation and acceptable validation of the model. However, parameters suggested in the methodology proposed by Esposito et al. (2011), Dell'Acqua et al. (2013b) and Russo et al. (2016), are also considered for statistical validation of the model and presented in following section.

Mean absolute deviation $M A D$ representing the summation of the absolute differences $D_{i}$ between observed and predicted $V_{85}$ divided by the total number of study sites $n$. It indicates the variability of the predicted $V_{85}$ value and is represented as:

$$
M A D=\frac{\sum_{i=1}^{n}\left|D_{i}\right|}{n} \text {. }
$$

Root mean squared error RMSE representing the square root of summation of $D_{i}^{2}$ divided by the total number of study sites $n$. It also indicates the variability of the predicted $V_{85}$ value and is represented as:

$$
R M S E=\sqrt{\frac{\sum_{i=1}^{n} D_{i}^{2}}{n} .}
$$

$I$-value representing $R M S E$ divided by the mean predicted $V_{85}$ value; this statistical indicator, calculated using

Table 6. Details of explanatory parameters used and observed vs predicted $V_{85}$ in validation

\begin{tabular}{|l|c|c|c|}
\hline \multirow{2}{*}{\multicolumn{1}{c|}{ Parameters }} & \multicolumn{3}{|c|}{ Site No } \\
\cline { 2 - 4 } & 16 & 17 & 18 \\
\hline$R[\mathrm{~m}]$ & 99 & 150 & 280 \\
\hline$P T L[\mathrm{~m}]$ & 70 & 55 & 316 \\
\hline Observed $V_{85}[\mathrm{~km} / \mathrm{h}]$ & 59 & 63 & 90 \\
\hline Predicted $V_{85}[\mathrm{~km} / \mathrm{h}]$ & 55 & 60 & 88 \\
\hline
\end{tabular}

Equation (4), suggests good prediction of the $V_{85}$, if less than 0.2 (Esposito et al. 2011; Dell'Acqua et al. 2013):

$$
I=\frac{R M S E}{\left(\frac{\sum_{i=1}^{n}\left(\text { predicted } V_{85}\right)_{i}}{n}\right)} .
$$

The obtained MAD, RMSE and I values are 3.28, 3.35 and 0.05 , respectively. For the $V_{85}$ prediction model validation, researchers have reported values of $M A D$ ranging from 4.44 to 15.00 and RMSE from 3.92 to 19.2 are satisfactory (Pérez-Zuriaga et al. 2010; Dell'Acqua, Russo 2010, Esposito et al. 2011; Jacob, Anjaneyulu 2013). Lower $M A D$ and $R M S E$ values indicate lesser error between predicted and actual $V_{85}$ values. In this case, the measured $M A D$ and RMSE values are low and should be acceptable. However, these are absolute values, not normalized based on the predicted values. The $I$-value, on the other hand, normalizes the error based on the predicted values. In this case, the obtained $I$-value of 0.05 (i.e., less than 0.2 ) indicates that the average error in the predicted $V_{85}$ is about $5 \%$ and may be considered as reasonable.

\section{Application of the developed model}

The developed speed prediction model indicates that the passenger car speed is proportional to circular curve radius $R$ and preceding tangent length PTL. This model is developed based on passenger car speed and geometric features of National Highways in India. The minimum and ruling design speed of these highways for flat terrain varies between 65 and $100 \mathrm{~km} / \mathrm{h}$ (IRC: 73-1980). Analysis of passenger car speed data indicates that the expected maximum $V_{85}$ of about $95 \mathrm{~km} / \mathrm{h}$ is observed for curves with radius 360 and $430 \mathrm{~m}$. Hence, various combinations of $R$ and PTL that yields passenger car speed between 65 and $95 \mathrm{~km} / \mathrm{h}$ is presented in Figure 5. The solid line in the plot indicates the minimum radius requirement, estimated using dynamic equilibrium condition represented in Equation (5). In this, the limiting values of superelevation $e$ (i.e., $7 \%$ ) and side friction $f$ (i.e., 0.15) are considered as recommended by Indian design guideline (IRC: 73-1980). The side friction value adopted is conservative for good pavement and weather conditions. Hence, in this situation, vehicles can safely travel at higher speed than the design speed of the highway. Overall, the solid line in Figure 5 restricts the radius for safe and conservative design. Therefore, designers can use this plot as a nomogram to come up with the combinations of horizontal curve radius and minimum preceding tangent length for the expected $V_{85}$ of passenger cars.

$$
e+f=\frac{V^{2}}{127 \cdot R},
$$

where: $R$ - radius $[\mathrm{m}] ; V$ - design speed $[\mathrm{km} / \mathrm{h}] ; e-\mathrm{su}-$ perelevation $[\%] ; f$ - coefficient of side friction. 
The developed model can be used for geometric design consistency evaluation and for developing consistent geometric design. The speed based geometric design consistency criteria proposed by Lamm et al. (1998) can be used for this purpose. According to this criteria, less than $10 \mathrm{~km} / \mathrm{h}$ difference between design $V_{d}$ and $V_{85}$ is rated as good, from 10 to $20 \mathrm{~km} / \mathrm{h}$ as fair and more than $20 \mathrm{~km} / \mathrm{h}$ as poor. A nomogram for the speed based geometric design consistency evaluation is presented in Figure 6. In this figure, the inclined solid line represents the minimum design speed corresponding to the absolute minimum curve radius. This is estimated using dynamic equilibrium condition represented in Equation (5). The superelevation $e$ and coefficient of side friction $f$ are considered as 0.07 and 0.15 , respectively (IRC: 73-1980). The other inclined lines represent the estimated $V_{85}$ for various combinations of $R$ and PTL. The dotted lines parallel to $x$-axis indicates the design speed of a facility. This nomogram is applicable for design speed ranging between 70 and $100 \mathrm{~km} / \mathrm{h}$. For a given combination of $R$ and PTL, the expected $V_{85}$ can be found from the inclined contour lines. It can be easily compared with the design speed represented by the horizontal lines and rated accordingly. For example, $300 \mathrm{~m}$ radius with $250 \mathrm{~m} P T L$ would yield $V_{85}$ of $86 \mathrm{~km} / \mathrm{h}$. If the highway is designed for 80 or $90 \mathrm{~km} / \mathrm{h}$ speed, the absolute difference between design and $V_{85}$ for this combination would remain within $10 \mathrm{~km} / \mathrm{h}$. Therefore, the highway segment with this combination can be rated as good for the design speed of 80 or $90 \mathrm{~km} / \mathrm{h}$.

Now, the nomogram in Figure 6 can also be used for consistency based geometric design. It would help in deciding appropriate combination of horizontal curve radius and preceding tangent length. For designs rated as good, a designer considers $V_{85}$ within $10 \mathrm{~km} / \mathrm{h}$ of the design speed. So, for design speed of $V_{d}[\mathrm{~km} / \mathrm{h}]$, the $V_{85}$ can vary between $V_{d} \pm 10 \mathrm{~km} / \mathrm{h}$, and the horizontal curve should meet the absolute minimum radius required for the design speed. The area in the nomogram representing these criteria can be used in the consistency based geometric design. Therefore, for the design speed of $80 \mathrm{~km} / \mathrm{h}$, the minimum radius required is $230 \mathrm{~m}$ and acceptable minimum and maximum $V_{85}$ is 70 and $90 \mathrm{~km} / \mathrm{h}$, respectively. The vertical line from "a" in Figure 6 represents the minimum radius for the design speed. Any radius selected for $R$ and PTL

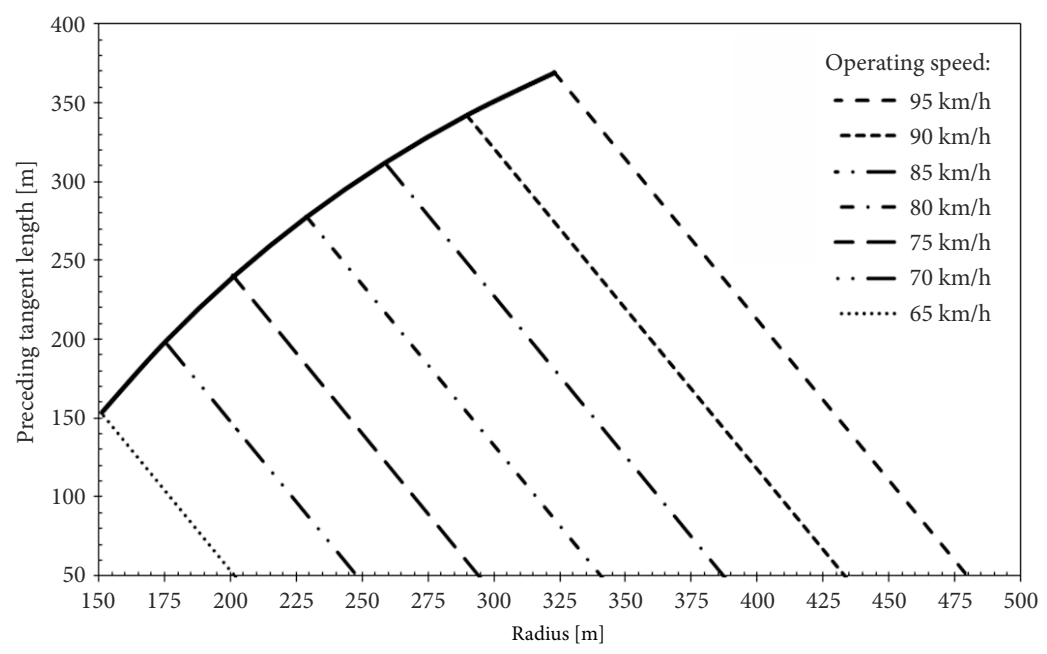

Figure 5. Nomogram for horizontal curve design

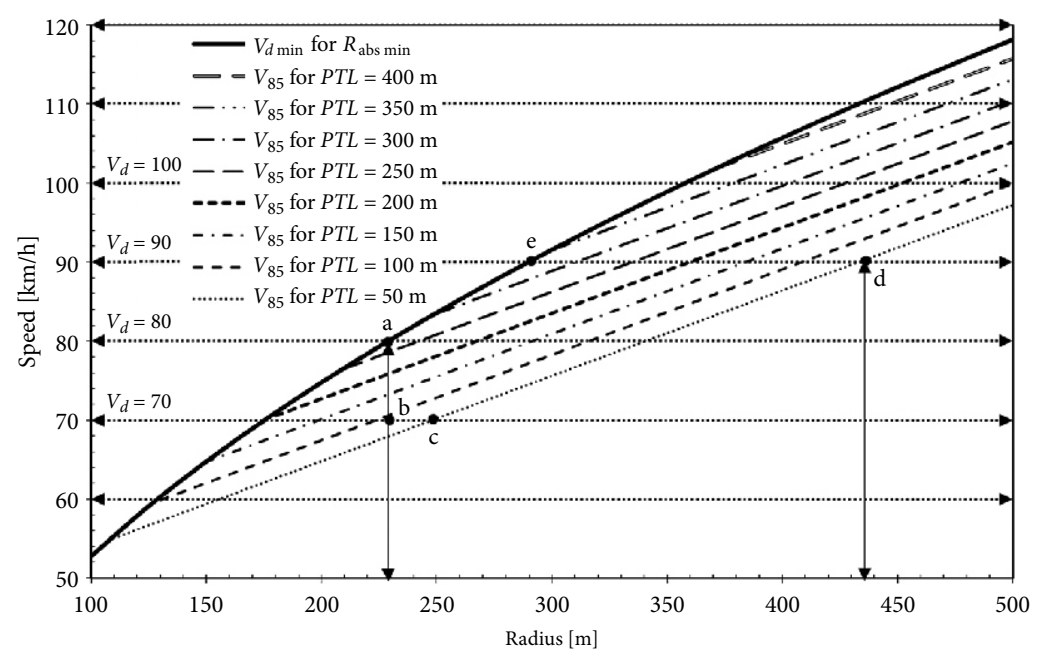

Figure 6. Nomogram for geometric design consistency evaluation 
combinations should be equal to or greater than the minimum radius for the design speed. The point " $b$ " and " $c$ " are the extreme combinations of $R$ and $P T L$ that meet the minimum radius for the design speed and the acceptable minimum $V_{85}$ (i.e., $70 \mathrm{~km} / \mathrm{h}$ ). Similarly, the point "d" and "e" represents the two extreme combinations of $R$ and PTL for the acceptable maximum $V_{85}$ (i.e., $90 \mathrm{~km} / \mathrm{h}$ ). Hence, the zone within " $\mathrm{a} \rightarrow \mathrm{b} \rightarrow \mathrm{c} \rightarrow \mathrm{d} \rightarrow \mathrm{e}$ " in Figure 6 represents the feasible combinations of $R$ and PTL for good geometric design consistency. A designer can use this information to develop the horizontal curve.

\section{Conclusions}

This study presents free flow speed data collection methodology for four-lane divided highway in which the subject vehicle can be influenced by its lead vehicles. For this, subject vehicle and vehicles in the adjacent lane or space are monitored in the video logs. The speed of subject vehicle is also obtained from the video logs and is used in developing the $V_{85}$ prediction model of passenger cars for four-lane divided horizontal curves. Only two geometric features (radius and preceding tangent length) are found to be significant for the $V_{85}$ of passenger cars at the centre of circular curve. The developed model indicates that longer PTL for a sharp curve should be avoided. This finding is in conformation with guidelines recommended by various highway geometric design manuals.

It is observed that the $V_{85}$ of passenger car remains about $95 \mathrm{~km} / \mathrm{h}$ for horizontal curves with radius 360 and $430 \mathrm{~m}$. Though this observation concurs with earlier research outcome on two-lane highway facilities (Krammes et al. 1995; Fitzpatrick, Collins 2000; Jacob, Anjaneyulu 2013), additional study at statistically significant number of locations representing four-lane divided highway facilities is required for any conclusive inference. Further, the vehicle speed data indicates that horizontal curve radius of $360 \mathrm{~m}$ or below affect $V_{85}$ of passenger car. The developed model is successfully validated with data from two different parts of the country. It ensures portability of the developed model. However, the proposed model is applicable for good weather and pavement conditions. Also, the model is valid only for the cross-section and other conditions considered in site selection. Further, a nomogram is prepared in this paper that can be used to come up with appropriate combination of radius and preceding tangent length for targeted $V_{85}$ of passenger cars. Also, a consistency evaluation nomogram has been proposed to identify possible combinations of $R$ and PTL for safe and consistent design.

The developed model is for passenger cars. Development of similar models for other vehicle types is essential for overall consistency evaluation and can be considered as future research scope. However, this model can be used for geometric design consistency evaluation for passenger cars. The effects of other vehicles, weather conditions, pavement conditions, etc. are not taken into account. Also, the model is valid for flat terrain. Further studies are needed to incorporate these shortcomings.

\section{Acknowledgements}

Authors would like to thank Mr. Ayush Tyagi, Mr. Mayank Prakash, Ms. Mounica Nagulapally and Mr. David Thangaraj for their support in data collection and extraction. Authors are also thankful to National Highways Authority of India for providing plan and profile, and Mumbai Nasik Expressway Limited (India) for providing support in field data collection.

We are grateful to the Indian Institute of Technology Bombay (India) for providing financial assistance to conduct the study.

\section{References}

AASHTO. 2011. A Policy on Geometric Design of Highways and Streets. 6th edition. American Association of State Highway and Transportation Officials (AASHTO), Washington, DC, US. $912 \mathrm{p}$.

Abbas, S. K. S.; Adnan, M. A.; Endut, I. R. 2011. Exploration of 85th percentile operating speed model on horizontal curve: a case study for two-lane rural highways, Procedia - Social and Behavioral Sciences 16: 352-363.

https://doi.org/10.1016/j.sbspro.2011.04.456

Abdul-Mawjoud, A. A.; Sofia, G. G. 2008. Development of models for predicting speed on horizontal curves for two-lane rural highways, Arabian Journal for Science and Engineering 33(2): 365-377.

Bangarraju, V. S. H.; Ravishankar, K. V. R.; Mathew, T. V. 2016. Analysis of lateral distance keeping behaviour in mixed traffic conditions with little lane discipline, International Journal for Traffic and Transport Engineering 6(4): 431-443. https://doi.org/10.7708/ijtte.2016.6(4).06

Bennett, C. R. 1994. A Speed Prediction Model for Rural TwoLane Highways: Dissertation. University of Auckland, New Zealand. $456 \mathrm{p}$.

Bonneson, J. A. 1999. Side friction and speed as controls for horizontal curve design, Journal of Transportation Engineering 125(6): 473-480.

https://doi.org/10.1061/(ASCE)0733-947X(1999)125:6(473)

Camacho-Torregrosa, F. J.; Pérez-Zuriaga, A. M.; Campoy-Ungría, J. M.; García-García, A. 2013. New geometric design consistency model based on operating speed profiles for road safety evaluation, Accident Analysis \& Prevention 61: 33-42. https://doi.org/10.1016/j.aap.2012.10.001

Campbell, J. L.; Lichty, M. G.; Brown, J. L.; Richard, C. M.; Graving, J. S.; Graham, J.; O’Laughlin, M.; Torbic, D.; Harwood, D. 2012. Human Factors Guidelines for Road Systems. National Cooperative Highway Research Program (NCHRP) Report 600. Transportation Research Board, Washington, DC, US. 319 p. Available from Internet: http://www.trb.org/Main/Blurbs/167909.aspx

Case, H. W.; Hulbert, S. F.; Mount, G. E.; Brenner, R. 1953. Effect of a roadside structure on lateral placement of motor vehicles, Highway Research Board Proceedings 32: 364-370.

Collins, J.; Fitzpatrick, K.; Bauer, K. M.; Harwood, D. W. 1999. Speed variability on rural two-lane highways, Transportation Research Record: Journal of the Transportation Research Board 1658: 60-69. https://doi.org/10.3141/1658-08

Dell'Acqua, G.; Busiello M.; Russo, F. 2013a. Safety data analysis to evaluate highway alignment consistency, Transportation Research Record: Journal of the Transportation Research Board 2349: 121-128. https://doi.org/10.3141/2349-14 
Dell'Acqua, G.; Russo, F.; Mauro, R. 2013b. Validation procedure for predictive functions of driver behaviour on two-lane rural roads, European Transport \Trasporti Europei 53: 1-13.

Dell'Acqua, G.; Russo, F. 2010. Speed factors on low-volume roads for horizontal curves and tangents, The Baltic Journal of Road and Bridge Engineering 5(2): 89-97. https://doi.org/10.3846/bjrbe.2010.13

Drew, D. R. 1968. Traffic Flow Theory and Control. McGraw Hill. $463 \mathrm{p}$.

Eboli, L.; Guido, G.; Mazzulla, G.; Pungillo, G. 2017. Experimental relationships between operating speeds of successive road design elements in two-lane rural highways, Transport 32(2): 138-145. https://doi.org/10.3846/16484142.2015.1110831

Esposito, T.; Mauro, R.; Russo, F.; Dell'Acqua, G. 2011. Speed prediction models for sustainable road safety management, Procedia - Social and Behavioral Sciences 20: 568-576. https://doi.org/10.1016/j.sbspro.2011.08.063

Figueroa Medina, A. M.; Tarko, A. P. 2005. Speed factors on twolane rural highways in free-flow conditions, Transportation Research Record: Journal of the Transportation Research Board 1912: 39-46. https://doi.org/10.1177/0361198105191200105

Fitzpatrick, K.; Collins, J. M. 2000. Speed-profile model for twolane rural highways, Transportation Research Record: Journal of the Transportation Research Board 1737: 42-49. https://doi.org/10.3141/1737-06

Fitzpatrick, K.; Elefteriadou, L.; Harwood, D. W.; Collins, J. M.; McFadden, J.; Anderson, I. B.; Krammes, R. A.; Irizarry, N.; Parma, K. D.; Bauer, K. M.; Passetti, K. 2000a. Speed Prediction for Two-Lane Rural Highways. Report No FHWARD-99-171. Federal Highway Administration (FHWA), US Department of Transportation, Washington, DC, US. 213 p. Available from Internet: https://www.fhwa.dot.gov/publications/research/safety/ihsdm/99171

Fitzpatrick, K.; Wooldridge, M. D.; Tsimhoni, O.; Collins, J. M.; Green, P.; Bauer, K. M.; Parma, K. D.; Koppa, R.; Harwood, D. W.; Anderson, I.; Krammes, R. A.; Poggioli, B. 2000b. Alternative Design Consistency Rating Methods for TwoLane Rural Highways. FHWA-RD-99-172. Federal Highway Administration (FHWA), US Department of Transportation, Washington, DC, US. 154 p. Available from Internet: https:// www.fhwa.dot.gov/publications/research/safety/ihsdm/99172

Fitzsimmons, E. J.; Kvam, V.; Souleyrette, R. R.; Nambisan, S. S.; Bonett, D. G. 2013a. Determining vehicle operating speed and lateral position along horizontal curves using linear mixedeffects models, Traffic Injury Prevention 14(3): 309-321. https://doi.org/10.1080/15389588.2012.701356

Fitzsimmons, E. J.; Souleyrette, R. R.; Nambisan, S. S. 2013 b. Measuring horizontal curve vehicle trajectories and speed profiles: pneumatic road tube and video methods, Journal of Transportation Engineering 139(3): 255-265. https://doi.org/10.1061/(ASCE)TE.1943-5436.0000501

Glennon, J. C.; Neuman, T. R.; Leisch, J. E. 1983. Safety and Operational Considerations for Design of Rural Highway Curves. FHWA-RD-83-035. Federal Highway Administration (FHWA), US Department of Transportation, Washington, DC, US. 339 p.

Gong, H.; Stamatiadis, N. 2008. Operating speed prediction models for horizontal curves on rural four-lane highways, Transportation Research Record: Journal of the Transportation Research Board 2075: 1-7. https://doi.org/10.3141/2075-01

Gunay, B. 2003. Methods to quantify the discipline of lanebased-driving, Traffic Engineering \& Control 44(1): 26-31.

Gunay, B. 2004. An investigation of lane utilisation on Turkish highways, Proceedings of the Institution of Civil Engineers Transport 157(1): 43-49.

https://doi.org/10.1680/tran.2004.157.1.43
Gunay, B. 2007. Car following theory with lateral discomfort, Transportation Research Part B: Methodological 41(7): 722735. https://doi.org/10.1016/j.trb.2007.02.002

Gunay, B. 2009. Rationality of a non-lane-based car-following theory, Proceedings of the Institution of Civil Engineers - Transport 162(1): 27-37. https://doi.org/10.1680/tran.2009.162.1.27

Hashim, I. H.; Abdel-Wahed, T. A.; Moustafa, Y. 2016. Toward an operating speed profile model for rural two-lane roads in Egypt, Journal of Traffic and Transportation Engineering (English Edition) 3(1): 82-88.

https://doi.org/10.1016/j.jtte.2015.09.005

IRC: 73-1980. Geometric Design Standards for Rural (Non-Urban) Highways. New Delhi, The Indian Roads Congress (IRC).

Islam, M. N.; Seneviratne, P. N. 1994. Evaluation of design consistency of two-lane rural highways, ITE Journal 64(2): 28-31.

Jacob, A.; Anjaneyulu, M. V. L. R. 2013. Operating speed of different classes of vehicles at horizontal curves on two-lane rural highways, Journal of Transportation Engineering 139(3): 287-294.

https://doi.org/10.1061/(ASCE)TE.1943-5436.0000503

Kerman, J. A.; McDonald, M.; Mintsis, G. A. 1982. Do vehicles slow down on bends? A study into road curvature, driver behaviour and design, in Transportation Planning Practice: Proceedings for Seminar held at the PTRC Summer Annual Meeting, 12-15 July 1982, Coventry, UK, 57-67.

Khan, S. I.; Maini, P. 1999. Modeling heterogeneous traffic flow, Transportation Research Record: Journal of the Transportation Research Board 1678: 234-341. https://doi.org/10.3141/1678-28

Krammes, R. A.; Brackett, R. Q.; Shafer, M. A.; Ottesen, J. L.; Anderson, I. B.; Fink, K. L.; Collins, K. M.; Pendleton, O. J.; Messer, C. J. 1995. Horizontal Alignment Design Consistency for Rural Two-Lane Highways. FHWA-RD-94-034. Federal Highway Administration (FHWA), US Department of Transportation, Washington, DC, US. 140 p.

Lamm, R.; Choueiri, E. M. 1987. Recommendations for evaluating horizontal design consistency based on investigations in the state of New York, Transportation Research Record: Journal of the Transportation Research Board 1122: 68-78.

Lamm, R.; Choueiri, E. M.; Hayward, J. C.; Paluri, A. 1988. Possible design procedure to promote design consistency in highway geometric design on two-lane rural roads, Transportation Research Record: Journal of the Transportation Research Board 1195: 111-122.

Lamm, R.; Choueiri, E. M.; Mailaender, T. 1990. Comparison of operating speeds on dry and wet pavements of two-lane rural highways, Transportation Research Record: Journal of the Transportation Research Board 1280: 199-207.

Lamm, R.; Psarianos, B.; Choueiri, E. M.; Soilemezoglou, G. 1998. A practical safety approach to highway geometric design international case studies: Germany, Greece, Lebanon, and the United States, in International Symposium on Highway Geometric Design Practices: Conference Proceedings, 30 August-1 September 1995, Boston, Massachusetts, US, 9-1-9-14.

Mahapatra, G.; Maurya, A. K. 2013. Study of vehicles lateral movement in non-lane discipline traffic stream on a straight road, Procedia - Social and Behavioral Sciences 104: 352-359. https://doi.org/10.1016/j.sbspro.2013.11.128

Mallikarjuna, C.; Rao, K. R. 2011. Heterogeneous traffic flow modelling: a complete methodology, Transportmetrica 7(5): 321-345. https://doi.org/10.1080/18128601003706078

Mathew, T. V.; Munigety, C. R.; Bajpai, A. 2015. Strip-based approach for the simulation of mixed traffic conditions, Journal of Computing in Civil Engineering 29(5). https://doi.org/10.1061/(ASCE)CP.1943-5487.0000378 
May, A. D. 1959. Friction concept of traffic flow, in Proceedings of the Thirty-Eighth Annual Meeting of the Highway Research Board, 5-9 January 1959, Washington, DC, US, 493-510.

McFadden, J.; Elefteriadou, L. 2000. Evaluating horizontal alignment design consistency of two-lane rural highways: development of new procedure, Transportation Research Record: Journal of the Transportation Research Board 1737: 9-17. https://doi.org/10.3141/1737-02

Memon, R. A.; Khaskheli, G. B.; Qureshi, A. S. 2008. Operating speed models for two-lane rural roads in Pakistan, Canadian Journal of Civil Engineering 35(5): 443-453.

https://doi.org/10.1139/L07-126

Misaghi, P.; Hassan, Y. 2005. Modeling operating speed and speed differential on two-lane rural roads, Journal of Transportation Engineering 131(6): 408-418.

https://doi.org/10.1061/(ASCE)0733-947X(2005)131:6(408)

Nama, S.; Maurya, A. K.; Maji, A.; Edara, P.; Sahu, P. K. 2016. Vehicle speed characteristics and alignment design consistency for mountainous roads, Transportation in Developing Economies 2: 23. https:/doi.org/10.1007/s40890-016-0028-3

Passetti, K. A.; Fambro, D. B. 1999. Operating speeds on curves with and without spiral transitions, Transportation Research Record: Journal of the Transportation Research Board 1658: 9-16. https://doi.org/10.3141/1658-02

Pérez-Zuriaga, A. M.; Camacho-Torregrosa, F. J.; García, A. 2013. Tangent-to-curve transition on two-lane rural roads based on continuous speed profiles, Journal of Transportation Engineering 139(11): 1048-1057. https://doi.org/10.1061/(ASCE)TE.1943-5436.0000583

Pérez-Zuriaga, A. M.; García, A.; Camacho-Torregrosa, F. J.; D’Attoma, P. 2010. Modeling operating speed and deceleration on two-lane rural roads with global positioning system data, Transportation Research Record: Journal of the Transportation Research Board 2171: 11-20. https://doi.org/10.3141/2171-02

Poe, C. M.; Tarris, J. P.; Mason, J. M. 1996. Relationship of Operating Speeds to Roadway Geometric Design Speeds. FHWARD-96-024. Federal Highway Administration (FHWA), US Department of Transportation, Washington, DC, US. 268 p.

Polgár, J.; Tettamanti, T.; Varga, I. 2013. Passenger number dependent traffic control in signalized intersections, Periodica Polytechnica Civil Engineering 57(2): 201-210. https://doi.org/10.3311/PPci.7175

Rawson, C. T. 2015. Procedures for Establishing Speed Zones. Manual Notice 2015-1. Texas Department of Transportation, Austin, Texas, US. 89 p. Available from Internet: http://onlinemanuals.txdot.gov/txdotmanuals/szn/szn.pdf

Russo, F.; Biancardo, S. A.; Busiello, M. 2016. Operating speed as a key factor in studying the driver behaviour in a rural context, Transport 31(2): 260-270.

https://doi.org/10.3846/16484142.2016.1193054

Russo, F.; Fric, S.; Biancardo, S. A.; Gavran, D. 2015. Driver speed behavior on circular curves of undivided two-lane rural roads: Serbian and Italian case studies, Transportation Research Record: Journal of the Transportation Research Board 2472: 117-128. https://doi.org/10.3141/2472-14

Schurr, K. S.; McCoy, P. T.; Pesti, G.; Huff, R. 2002. Relationship of design, operating, and posted speeds on horizontal curves of rural two-lane highways in Nebraska, Transportation Research Record: Journal of the Transportation Research Board 1796: 60-71. https://doi.org/10.3141/1796-07

Steyer, R. 1998. Design criteria for curves on two-lane rural highways, in International Symposium on Highway Geometric Design Practices: Conference Proceedings, 30 August-1 September 1995, Boston, Massachusetts, US, 25-1-25-8.
Taragin, A.; Leisch, L. E. 1954. Driver performance on horizontal curves, in Proceedings of the Thirty-Third Annual Meeting of the Highway Research Board, 12-15 January 1954, Washington, DC, US, 446-466.

Tettamanti, T.; Varga, I. 2014. Mobile phone location area based traffic flow estimation in urban road traffic, Advances in Civil and Environmental Engineering 1(1): 1-15.

Torbic, D. J.; Harwood, D. W.; Gilmore, D. K.; Pfefer, R.; Neuman, T. R.; Slack, K. L.; Hardy, K. K. 2004. Guidance for Implementation of the AASHTO Strategic Highway Safety Plan. Volume 7: A Guide for Reducing Collisions on Horizontal Curves. National Cooperative Highway Research Program (NCHRP) Report 500. Transportation Research Board (TRB), Washington, DC, US. 85 p. https://doi.org/10.17226/13545

TRB. 2010. Highway Capacity Manual. 5th edition. Transportation Research Board (TRB), Washington, DC, US. 1650 p.

Voigt, A. 1996. Evaluation of Alternative Horizontal Curve Design Approaches for Rural Two-Lane Highways. Report No 046903. Texas Transportation Institute, Texas A\&M University System, Arlington, TX, US. 110 p. Available from Internet: https://static.tti.tamu.edu/tti.tamu.edu/documents/04690-3.pdf

Voigt, A.; Krammes, R. A. 1996. An operational and safety evaluation of alternative horizontal curve design approaches on rural two-lane highways, in International Symposium on Highway Geometric Design Practices: Conference Proceedings, 30 August-1 September 1995, Boston, Massachusetts, US, 11-1-11-8.

Watters, P.; O’Mahony, M. 2007. The relationship between geometric design consistency and safety on rural single carriageways in Ireland, in Proceedings of the European Transport Conference (ETC) 2007, 17-19 October 2007, Leiden, The Netherlands, 1-15. 